\title{
Could radial extracorporeal shock wave therapy have an effect on wound healing in clinical practice by creating genotoxic damage? An in vitro study in mouse fibroblasts
}

\author{
Ekin Kaya Şimşek, $M^{1}{ }^{1}$, Bahtiyar Haberal, $M^{1}{ }^{1}$, Yeşim Korkmaz Kasap, MD $^{2}$ (D) Erkan Yurtcu, MD $^{3}$ (D) \\ ${ }^{1}$ Department of Orthopedics and Traumatology, Başkent University, Faculty of Medicine, Ankara, Turkey \\ ${ }^{2}$ Department of Medical Biology, Başkent University, Faculty of Medicine, Ankara, Turkey \\ ${ }^{3}$ Department of Medical Biology, Kırıkkale University, Faculty of Medicine, Kırıkkale, Turkey
}

Extracorporeal shock wave therapy (ESWT) is a noninvasive treatment method using sound waves to stimulate healing. The number of studies in the literature has increased, since the date of the use of shock wave therapy in the field of urology for lithotripsy and its effects have been better understood. ${ }^{[1]}$ Currently, ESWT is actively used in orthopedics and traumatology clinics in the treatment of many different musculoskeletal pathologies. In the literature, the applications mainly focus on bone, tendon, and soft tissue. The first applications on bone tissue started with nonunion and delayed healing case series, ${ }^{[2-5]}$ followed by applications on osteochondrosis dissecans, ${ }^{[6]}$ osteonecrosis, ${ }^{[7]}$ bone marrow edema. ${ }^{[8,9]}$ Applications on tendon tissue are often performed on plantar fasciitis. ${ }^{[10,11]}$ Achilles tendinopathy, ${ }^{[4,12]}$

Received: June 21, 2021

Accepted: October 04, 2021

Published online: November 19, 2021

Correspondence: Bahtiyar Haberal, MD. Başkent Üniversitesi Tıp Fakültesi Ortopedi ve Travmatoloji Anabilim Dalı, 06490

Bahçelievler, Ankara, Türkiye.

E-mail: bahtiyarhaberal@hotmail.com

Doi: $10.52312 /$ jdrs.2021.315

Citation: Şimşek EK, Haberal B, Korkmaz Kasap Y, Yurtcu E. Could radial extracorporeal shock wave therapy have an effect on wound healing in clinical practice by creating genotoxic damage? An in vitro study in mouse fibroblasts. Jt Dis Relat Surg 2021;32(3):658-667.

(O2021 All right reserved by the Turkish Joint Diseases Foundation

This is an open access article under the terms of the Creative Commons Attribution-NonCommercial License, which permits use, distribution and reproduction in any medium, provided the original work is properly cited and is not used for commercial purposes (http://creativecommons.org/licenses/by-nc/4.0/).

\section{ABSTRACT}

Objectives: This study aims to evaluate wound healing effects of in vitro radial extracorporeal shock wave (rESW) application on mouse fibroblasts and whether the cytotoxic effect of extracorporeal shock wave (ESW) was due to a possible genotoxic effect.

Patients and methods: After creating an in vitro wound healing model in L929 mouse fibroblast culture, fibroblasts were stimulated with a frequency of $3 \mathrm{~Hz}$, and 100, 250, 500, 1,000 and 1,500 pulses shock waves were applied. Energy flux densities ranging from 0.01 to $0.23 \mathrm{~mJ} / \mathrm{mm}^{2}(14.3 \mathrm{MPa})$ at a constant pressure level of 0.5 and 1 bar were applied. Wound healing, cell viability, and genotoxicity were evaluated at 24 and $48 \mathrm{~h}$.

Results: All shot numbers for both pressures significantly reduced cell viability $(\mathrm{p}<0.05)$. For both 0.5 and 1 bar pressures, in both intervals, the rate of wound healing decreased, regardless of the number of shots $(\mathrm{p}<0.05)$. In vitro genotoxic damage was detected at both 0.5 and 1 bar pressures, in both time intervals, regardless of the number of shots. The genotoxic damage increased from 24 to $48 \mathrm{~h}$.

Conclusion: The study results suggest that, when ESWT is applied in this in vitro experimental setup, cell viability decreases and wound healing is delayed under all conditions. Furthermore, genotoxic damage can be prevented by using shots below 1,000 pulses. Therefore, while investigating the therapeutic effect of ESW therapy in vitro, the upper limit for the number of shots should be 1,000 pulses.

Keywords: Cell viability, extracorporeal shock wave therapy, genotoxicity, in vitro, wound healing.

calcifying tendinitis ${ }^{[13]}$ and lateral epicondylitis. ${ }^{[14,15]}$ On the other hand, soft tissue applications focused on chronic wounds, ${ }^{[16]}$ scar tissues ${ }^{[17]}$ and hypertrophic wounds. ${ }^{[18]}$

The high-amplitude sound waves (shock waves) used in ESWT is the result of a transient pressure 
change resulting from a sudden increase in ambient pressure in three-dimensional space. These shock waves have a peak pressure of about 1,000 times higher in terms of their physical properties than ultrasound waves. It is known that the effect of shock waves on the tissue occurs in four phases. In the physical phase, extracellular cavitation, ionized molecules, and membrane permeability increase due to the direct effect of shock waves. In the physicochemical phase, interaction occurs with spreadable radicals and biomolecules. In the chemical phase, intracellular reactions and molecular changes occur and, finally, the biological phase occurs. ${ }^{[19]}$

Two ty pes of focused (f) and radial (r) extracorporeal shock waves (ESW) are used in the clinic. In focused ESW (fESW), shock waves from a large shockwave source are directed to a single targeted point, whereas in radial ESW (rESW), shock waves from the source propagate as expanding waves in three-dimensional space and reach the targeted point and surrounding regions (Figure 1). ${ }^{[20]}$

Wound healing refers to a complex process in which inflammatory reactions, proliferation and remodeling occur. In the proliferative phase of wound healing, collagen synthesis increases with rapid fibroblast proliferation in response to chemotactic factors synthesized during the inflammatory phase. In addition, capillaries formed by angiogenesis contribute to the formation of granulation tissue. In the remodeling phase, collagen synthesis is maintained by fibroblasts and wound healing is completed. ${ }^{[21]}$ Several studies have shown that ESWT increases the growth rate of fibroblast via messenger ribonucleic acid (mRNA) expression level and increases collagen type I and type III synthesis in fibroblasts in a dosedependent manner. These increase the interest in ESW application in the treatment of wound healing problems. ${ }^{[16,17,22-24]}$

There are theories related to the cellular explanation of how shock waves increase wound healing; however, there is no consensus in the literature. In a limited number of studies, it has been shown that ESW application may have a cytotoxic effect and it has been suggested that this is caused by both the mechanical cavitation effect and triggering the pro-inflammatory response and catabolic process in cells. As a result of this process, tissue healing mechanisms have been proposed to be activated. ${ }^{[25]}$

In the present study, we hypothesized that ESW application had genotoxic effects on cells. We, therefore, aimed to evaluate wound healing effects of in vitro rESW application on mouse fibroblasts and whether the cytotoxic effect of ESW was due to a possible genotoxic effect. To the best of our knowledge, this is the first study in the literature to examine possible genotoxic effects of in vitro rESW application on mouse fibroblasts.

\section{PATIENTS AND METHODS}

This study was approved by the Başkent University, Faculty of Medicine University, Institutional Review Board (No: 94603339-604.01.02/1985).

\section{Cell culture}

The L929 mouse fibroblasts (CCL-1, ATCC, Rockville, USA) were cultured in RPMI 1640 medium (Biochrome AG, Berlin, Germany) supplemented with heat inactivated $10 \%$ fetal bovine serum (FBS; Biochrom AG, Berlin, Germany), and antibiotic $\operatorname{mix}(10,000 \mathrm{U} / \mathrm{mL}$ penicillin and $10,000 \mu \mathrm{g} / \mathrm{mL}$ streptomycin, Biological Industries, Israel) in a $95 \%$ humidified incubator (Heraeus Deutschland $\mathrm{GmbH}$ \& Co. KG, Hanau, Germany). Cells were subcultured every $24 \mathrm{~h}$ and cells at the 5 to 10 passage level were used in the study.

\section{rESW treatment}

The shock-wave generator (Masterpuls ${ }^{\circledR}$ MP100; Storz Medical, Switzerland) used in orthopedics and traumatology clinic used for the in vitro experiments. Shock wave application was performed using a $15-\mathrm{mm}$ diameter radial shock wave transmitter (Model No: R15, Storz Medical), which has a tissue penetration of $\geq 30 \mathrm{~mm}$ and has proven to have a therapeutic effect. The shock wave applications were performed as previously described with minor modifications (Figure 2). ${ }^{[16]}$ Briefly, cells were seeded in a $9 \mathrm{~cm}^{2}$ sterile Petri dishes. After cells were reached 95\% confluency,

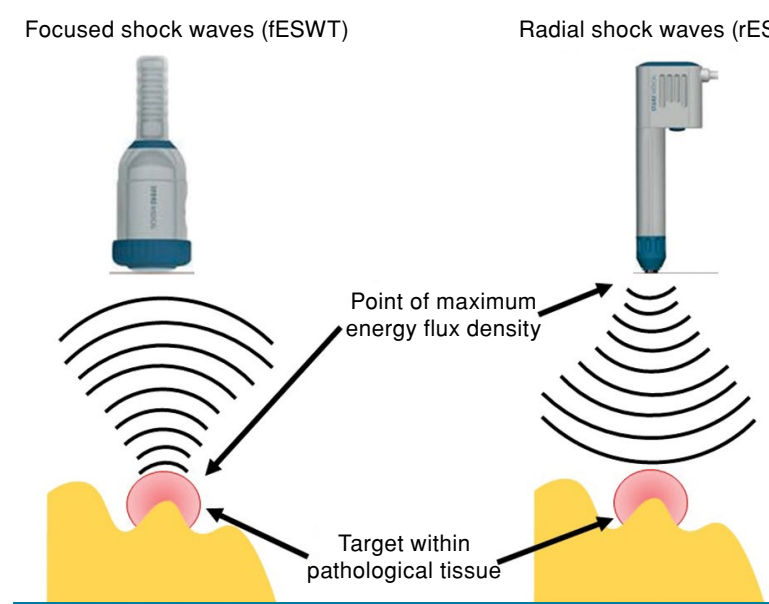

FIGURE 1. Mechanism of action of focused and radial extracorporeal shock wave technology. 

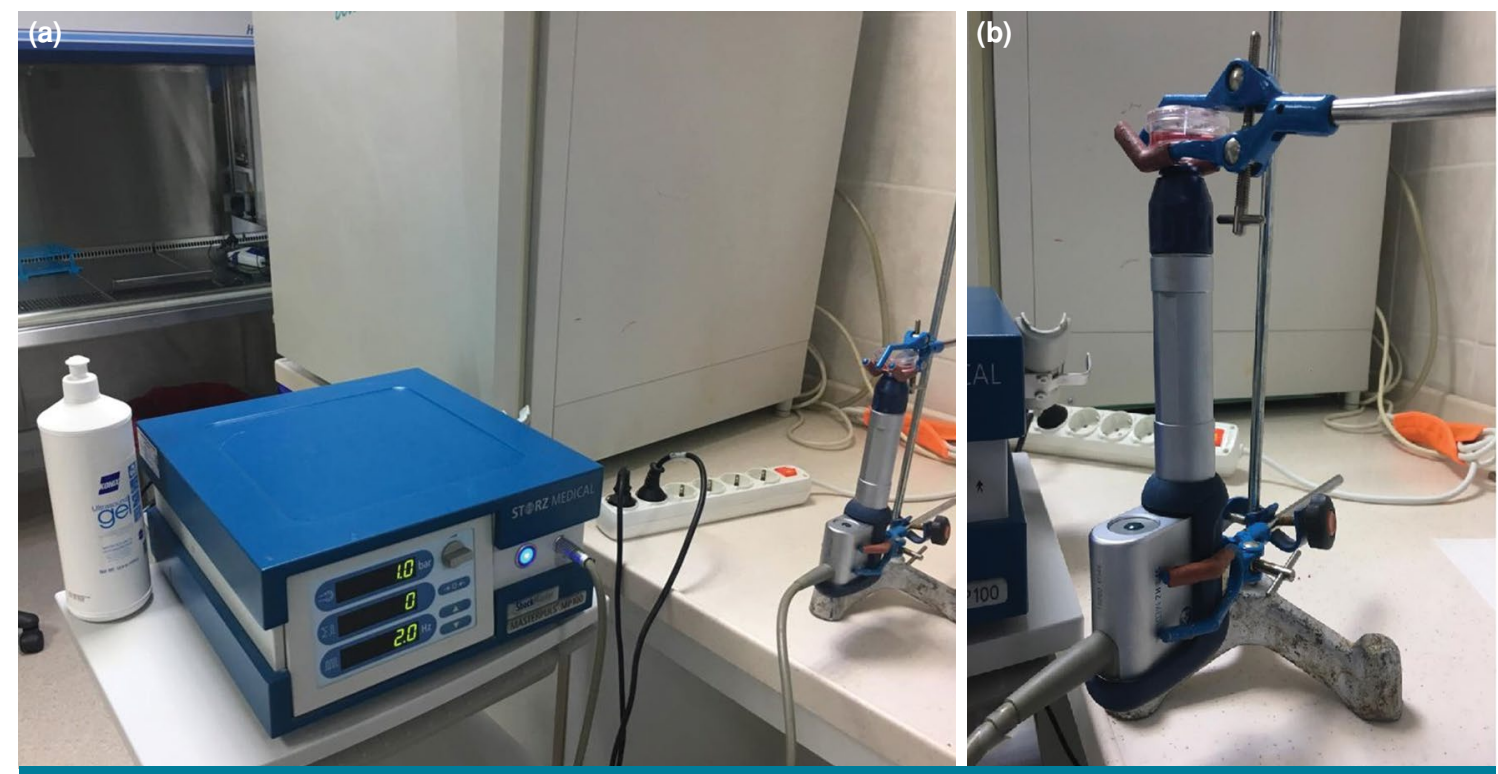

FIGURE 2. Experimental setup in which shock wave is applied to cell cultures. (a) Experimental setup. (b) Shock wave application to cell cultures.

they were stimulated with a frequency of $3 \mathrm{~Hz}$ and $100,250,500,1,000$, and 1,500 pulses of shock waves. Energy flux densities ranging from 0.01 to $0.23 \mathrm{~mJ} / \mathrm{mm}^{2}$ $(14.3 \mathrm{MPa})$ at a constant pressure level of 0.5 and 1 bar were applied. This experimental protocol was determined by examining the number and frequency of shock wave pulses used in previous studies to make a detailed evaluation in cell culture. ${ }^{[2,16,26-28]}$ Additionally, separate cell cultures are used for each pulse shock and pressure level. Energy transfer from the radial (r)ESWT transmitter to the Petri dish was maximized by coating the surface of the Petri dishes with coupling agent. The rESWT application was performed at 24-h intervals, until the in vitro wound sites were closed (for two days). The cell cultures to be used in the study were, then, plated and an in vitro wound model was created, and the rESWT was not applied to the cell cultures in the control group. Evaluation of in vitro wound healing in the control group was performed blindly by a researcher familiar with this method, but not involved in the study to avoid bias.

\section{In vitro scratch assay (wound healing)}

The L929 cells were seeded in a Petri dish, and scratch wounds were made using a sterile 0.1 to $10 \mu \mathrm{L}$ pipette tip in fibroblast cell culture and, then, the closure time and percentage of the scratch wounds were evaluated as previously described. ${ }^{[29]}$ Scratch wounds area was photographed using an inverted microscope (Olympus IX73, Japan) at 24-h intervals and analyzed by Image version $1.53 \mathrm{k} 14$ (University of Wisconsin, Madison, WI, USA) software. For quantification, the area in the wound edges was measured at least of four areas for each application, and the mean values were calculated (d). The percentage of wound healing (WH) was calculated as follows:

$\mathrm{WH} \%=\left[\left(\mathrm{d}_{\text {original wound }}-\mathrm{d}_{\text {healing }}\right) / \mathrm{d}_{\text {original wound }}\right] \times 100$

Under in vitro conditions, scratch wounds that do not have any rESW treatment close within $48 \mathrm{~h}$ (Figure 3). Therefore, we determined the follow-up period as $48 \mathrm{~h}$ in our study.

\section{Determination of cell viability}

Cytotoxic effects of rESWT application were determined using 3-[4.5-thiazol-2-yl]-2.5-diphenylte trazolium bromide (Sigma-Aldrich Inc., St Louis, MO, USA). Briefly, following the application in specified time and conditions, $5 \mu \mathrm{L}$ of $5 \mathrm{mg} / \mathrm{mL}$ MTT were added to total of $1 \times 104$ cells (final volume $0.59 \mathrm{mg} / \mathrm{mL}$ ) and the cells were incubated at $37^{\circ} \mathrm{C}$ for $4 \mathrm{~h}$. At the end of the incubation, $100 \mu \mathrm{L} 10 \%$ of sodium dodecyl sulfate solution was added to cells and a final incubation step was carried out at $37^{\circ} \mathrm{C}$ for $16 \mathrm{~h}$. Optical density of the chromogenic product was determined at $540 \mathrm{~nm}$ in a spectrophotometer (Epoch ${ }^{\mathrm{TM}}$; BioTek Instruments Inc., VT, USA) and viability of cells was calculated using spectrophotometer outcomes.

\section{Assay for genotoxicity (Comet assay)}

Genotoxic effects of rESWT application were determined by alkaline single-cell gel electrophoresis 

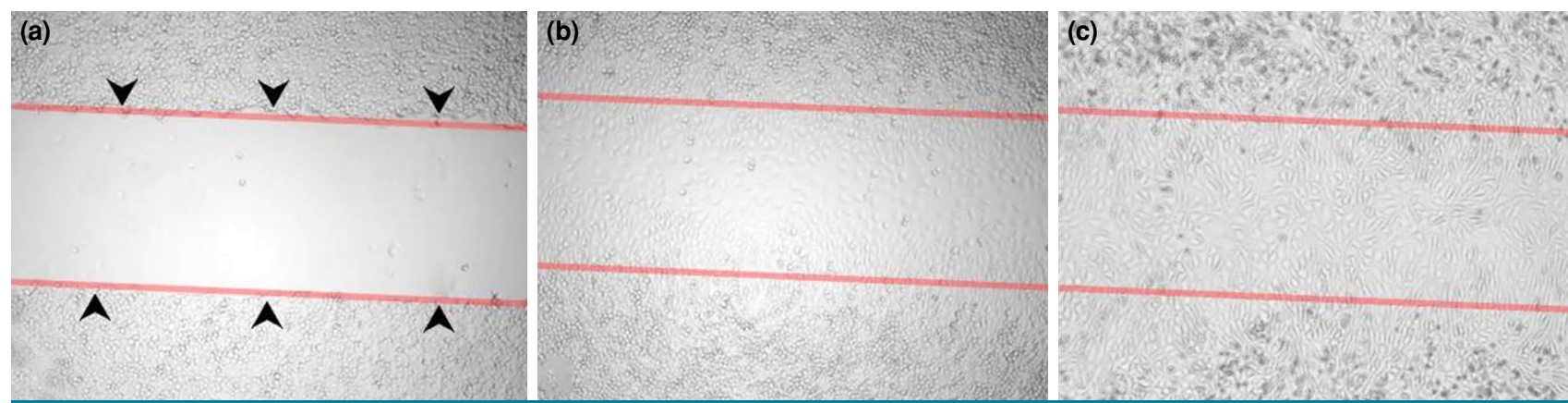

FIGURE 3. Representative images of single-cell gel electrophoresis assay. (a) In vitro wound model created in fibroblast culture with pipette tip: Cell-free area between both red lines marked with black arrows. (b) Partial invasion of the cell-free area (in vitro wound) between both red lines by fibroblasts at $24 \mathrm{~h}$. (c) Complete invasion of the cell-free area (in vitro wound) between both red lines by fibroblasts at $48 \mathrm{~h}$.

method (SCGE; comet assay) as previously described..$^{[30]}$ Briefly, trypsinized cells were resuspended in phosphate-buffered saline (PBS) and mixed with $1 \%(\mathrm{w} / \mathrm{v})$ low melting point agarose (LMPA; Sigma-Aldrich Corp., MO, USA). After this step, the cells were spread out on to the pre-coated slides with $0.5 \%(\mathrm{w} / \mathrm{v})$ normal melting point agarose (NMPA; Sigma-Aldrich Corp., MO, USA). For the solidification of agarose slides placed with coverslips were put on ice packs. After the solidification of agarose coverslips were removed and third layer of LMPA was added on to the slides. After the incubation in lysis solution (10 mM Tris, $100 \mathrm{mM}$ ethylenediaminetetraacetic acid (EDTA) disodium salt and $2.5 \mathrm{M}$ sodium chloride; $\mathrm{pH} 10$ ) for $2 \mathrm{~h}$ at $4^{\circ} \mathrm{C}$ (dark), slides were incubated in an electrophoresis buffer (1 mM EDTA disodium salt, $300 \mathrm{mM}$ sodium hydroxide; $\mathrm{pH}>13$ ) for $20 \mathrm{~min}$ in the dark in an opaque electrophoresis tank. Following the electrophoresis which was carried out at $300 \mathrm{~mA}$ for $30 \mathrm{~min}$, slides were neutralized (0.4 M Tris; $\mathrm{pH}$ 7.5) and stained with ethidium bromide $(2 \mu \mathrm{g} / \mathrm{mL})$. One hundred nuclei were blindly scored using a fluorescence microscope (Nikon, Eclipse 600, Japan) and this process was repeated three times for each treatment.
Thus, a total of 300 nuclei were scored. By the visual scoring, nuclei were categorized regarding to shape and comet tail. Undamaged, i.e., intact nuclei have globular shape were scored as 0 , extremely damaged nuclei were scored as 4+ (Figure 4). Each counted nucleus was multiplied by its score, and total scores were expressed as arbitrary units (AU).

\section{Statistical analysis}

Statistical analysis was performed using the IBM SPSS for Windows version 25.0 software (IBM Corp., Armonk, NY, USA). Descriptive data were expressed in mean \pm standard deviation (SD), median (min-max) or number and frequency. Normality assumption was tested using the Kolmogorov-Smirnov normality test. After evaluating whether the data were suitable for the parametric test, t-test was used for parametric data and Wilcoxon signed-rank test was used for non-parametric data. Analysis of variance was used in factorial order for comparisons of the means. If the prerequisites of parametric tests (analysis of variance in factorial order) were not met, the data were analyzed with the general linear model. A two-tailed $p$ value of $<0.05$ was considered statistically significant.

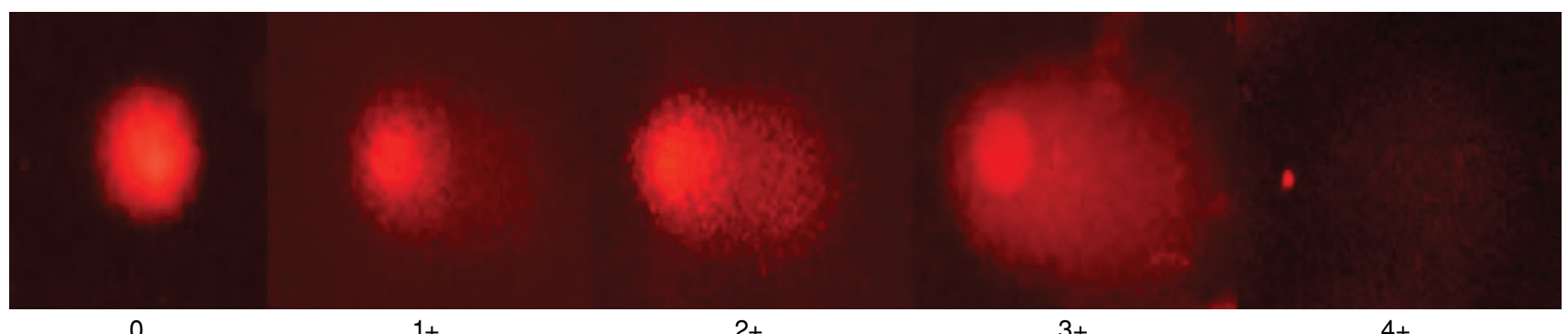

FIGURE 4. Representative images of single-cell gel electrophoresis assay. 

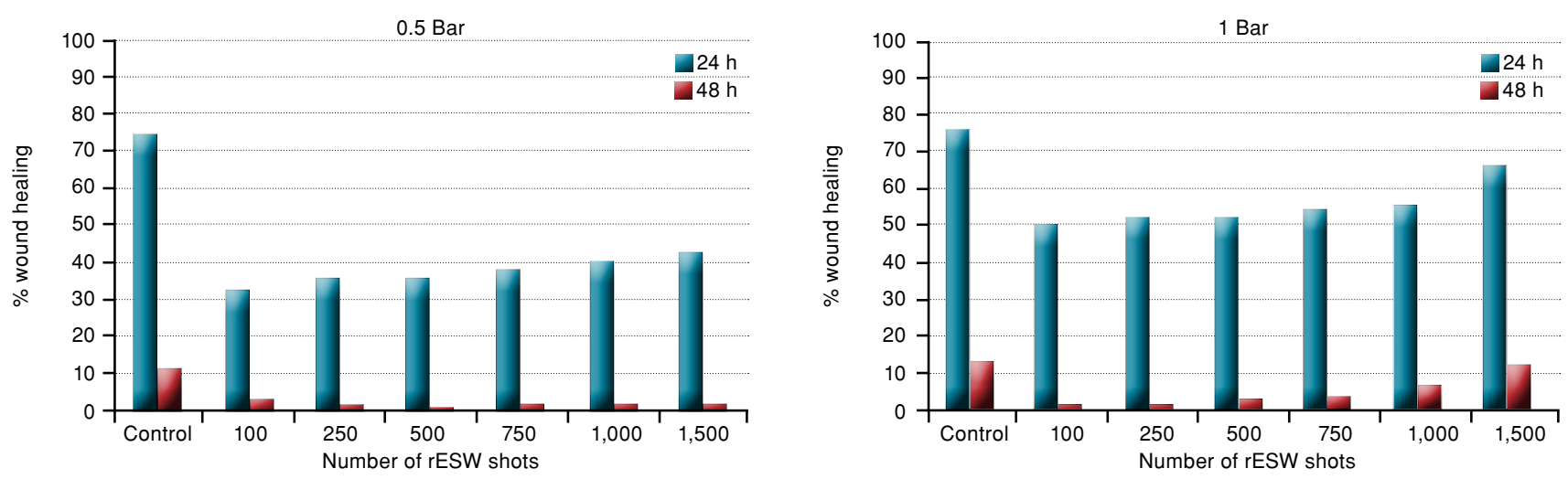

FIGURE 5. Representative images of wound closure rate of scratch assay. Scratch areas were captured at 24-h intervals and evaluated. In both graphs, the $y$-axis shows the percentage patency of the wound.

rESWT: Radial extracorporeal shock wave therapy.

\section{RESULTS}

\section{Effects of rESW on wound healing (In vitro scratch assay)}

When the control group and the 0.5 bar pressure group were compared, the wound healing rate at the 24 and $48 \mathrm{~h}$ decreased, regardless of the number of shots. However, when the control group and the 1 bar pressure group were compared, the wound healing rate decreased at 24 and $48 \mathrm{~h}$, similarly to the 0.5 bar applied group, regardless of the number of shots (Figure 5). The $p$ values obtained as a result of statistical comparison of both groups with the control group are given in Table I.

\section{Effects of rESW on cell viability}

According to the general linear model analysis, when 100 shots were applied in the 0.5 and 1 bar pressure group, there was no significant difference in viability between the control group and the experimental groups $(p=0.122)$. When $\geq 250$ shots were exceeded, the viability decreased significantly after the $24 \mathrm{~h}$ compared to the control group, regardless of the pressure (Table II). The lowest viability values were reached in 1,500 shots at each pressure level (Figure 6).

\section{Effects of rESW on genotoxic damage (Comet assay)}

In vitro genotoxic damage was assessed at both 0.5 and 1 bar pressures, in both time intervals,

\begin{tabular}{|c|c|c|c|c|c|c|c|}
\hline \multicolumn{8}{|c|}{ TABLE I } \\
\hline & \multirow[t]{2}{*}{ Control vs. } & $0-24 \mathrm{~h}$ & $0-24 \mathrm{~h}$ & $0-48 \mathrm{~h}$ & $0-48 \mathrm{~h}$ & $24-48 \mathrm{~h}$ & $24-48 \mathrm{~h}$ \\
\hline & & $p$ & Mean $\pm S D$ & $p$ & Mean \pm SD & $p$ & Mean $\pm S D$ \\
\hline \multirow{6}{*}{ 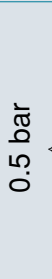 } & 100 & $0.005^{*}$ & $5259601.50 \pm 3225384.97$ & $0.001^{*}$ & $7532564.88 \pm 1260227.48$ & $0.001^{*}$ & $2272963.38 \pm 2480397.17$ \\
\hline & 250 & $0.012^{\star *}$ & $4702930.25 \pm 2379211.37$ & $0.012^{\star *}$ & $7168327.25 \pm 1168250.99$ & $0.012^{\star *}$ & $2465397.00 \pm 2064067.82$ \\
\hline & 500 & $0.001^{*}$ & $4723806.88 \pm 2233347.21$ & $0.001^{*}$ & $7253320.25 \pm 1372915.97$ & $0.015^{\star}$ & $2529513.38 \pm 2234489.71$ \\
\hline & 750 & $0.012^{* *}$ & $4763945.50 \pm 3430106.49$ & $0.012^{* *}$ & $7409069.88 \pm 1811918.77$ & $0.012^{\star *}$ & $2645124.38 \pm 2564325.46$ \\
\hline & 1000 & $0.012^{* *}$ & $3978795.50 \pm 3423041.93$ & $0.012^{* *}$ & $6387547.88 \pm 1126229.31$ & $0.012^{* *}$ & $2408752.38 \pm 2715997.14$ \\
\hline & 1500 & $0.012^{* *}$ & $4166815.00 \pm 2562602.56$ & $0.012^{\star *}$ & $7002917.63 \pm 893627.73$ & $0.012^{* *}$ & $2836102.62 \pm 2694849.72$ \\
\hline \multirow{6}{*}{ 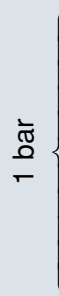 } & 100 & $0.017^{* *}$ & $3604867.00 \pm 3484374.23$ & $0.012^{* *}$ & $7000993.75 \pm 911799.22$ & $0.012^{* *}$ & $3396126.75 \pm 3206028.09$ \\
\hline & 250 & $0.001^{*}$ & $3901035.25 \pm 1613607.30$ & $0.001^{*}$ & $7645078.00 \pm 1178166.47$ & $0.003^{*}$ & $3744042.75 \pm 2388005.43$ \\
\hline & 500 & $0.017^{* *}$ & $3124100.63 \pm 2640394.76$ & $0.012^{* *}$ & $6311927.63 \pm 628624.39$ & $0.012^{* *}$ & $3187827.00 \pm 2746801.96$ \\
\hline & 750 & $0.036^{* *}$ & $3093055.00 \pm 3112098.01$ & $0.012^{* *}$ & $6449591.63 \pm 889393.50$ & $0.012^{* *}$ & $3356536.63 \pm 3017819.26$ \\
\hline & 1000 & $0.012^{* *}$ & $3134051.7516 \pm 69308.60$ & $0.012^{* *}$ & $6507387.63 \pm 1056586.79$ & $0.012^{* *}$ & $3373335.88 \pm 794965.93$ \\
\hline & 1500 & $0.025^{\star *}$ & $2410278.13 \pm 2523595.19$ & $0.012^{* *}$ & $6133526.00 \pm 1660161.12$ & $0.012^{\star *}$ & $3723247.88 \pm 1319097.14$ \\
\hline
\end{tabular}




\begin{tabular}{|c|c|c|c|}
\hline \multicolumn{4}{|c|}{$\begin{array}{l}\text { Comparison of cell viability rates between control and } \\
\text { experimental groups according to the number of shots and } \\
\text { time intervals }\end{array}$} \\
\hline & Control vs. & $p$ & Mean difference \\
\hline \multirow{6}{*}{ 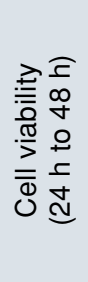 } & 100 shots & 0.122 & 0.049 \\
\hline & 250 shots & 0.024 & $0.072^{*}$ \\
\hline & 500 shots & 0.009 & $0.084^{*}$ \\
\hline & 750 shots & 0.002 & $0.102^{*}$ \\
\hline & 1,000 shots & 0.001 & $0.124^{*}$ \\
\hline & 1,500 shots & 0.001 & $0.154^{*}$ \\
\hline
\end{tabular}

regardless of the number of shots. Genotoxic damage was increased progressively from 24 to $48 \mathrm{~h}$. The results are shown in Table III.

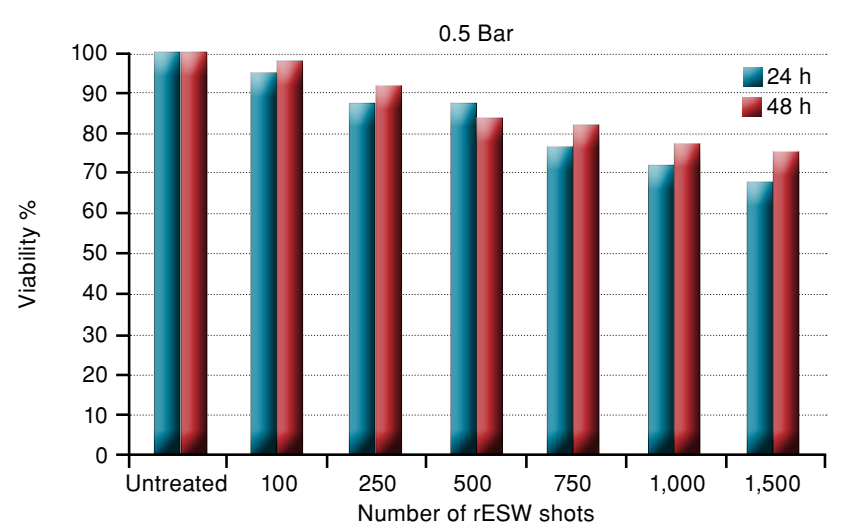

Genotoxic damage observed in $24 \mathrm{~h}$ at $0.5 \mathrm{bar}$ and $100(\mathrm{p}=1.000), 250(\mathrm{p}=0.558), 500(\mathrm{p}=0.135)$, and 750 $(\mathrm{p}=0.099)$ shots were similar to the control group, while significant genotoxic damage was observed in the 1,000 and 1,500 shots. On the other hand, higher genotoxic damage rate was detected at the end of $48 \mathrm{~h}$ in both groups compared to the control group (Table IV).

When the pressure was increased to 1 bar, a significant genotoxic damage occurred even at 100 shots, unlike 0.5 bar pressure application in the 24-h evaluation. A significant genotoxic damage occurred in all groups below this pressure, regardless of the number of shots and the duration (Table IV).

In addition, the univariate analysis of variance revealed the genotoxic damage per shot count with 1.0 bar pressure which was significantly higher than the genotoxic damage per shot with 0.5 bar pressure (Table V).

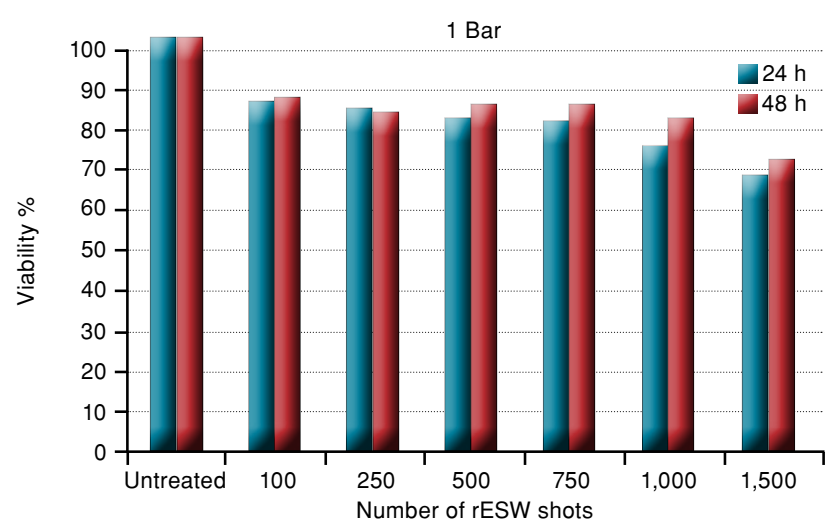

FIGURE 6. Effects of rESWT application on the in vitro wound healing of L929 cells for 24 and $48 \mathrm{~h}$ at 0.5 and 1 bar pressures. rESWT: Radial extracorporeal shock wave therapy.

\begin{tabular}{|c|c|c|c|c|}
\hline & & $\begin{array}{r}\text { TABLE } \\
\text { (comet) score }\end{array}$ & \pm SEM) & \\
\hline & & & & \\
\hline & 0.5 bar & 1 bar & 0.5 bar & 1 bar \\
\hline & Mean \pm SEM & Mean $\pm S E M$ & Mean \pm SEM & Mean \pm SEM \\
\hline Control & $7.50 \pm 2.158$ & $7.50 \pm 2.158$ & $4.167 \pm 0.926$ & $4.167 \pm 0.926$ \\
\hline 100 & $7.50 \pm 2.158$ & $15.833 \pm 1.747$ & $10.333 \pm 0.926$ & $25.667 \pm 2.437$ \\
\hline 250 & $9.17 \pm 2.158$ & $20.167 \pm 1.747$ & $13.833 \pm 0.926$ & $25.5 \pm 2.437$ \\
\hline 500 & $12.17 \pm 2.158$ & $21.167 \pm 1.747$ & $15.833 \pm 0.926$ & $25.5 \pm 2.437$ \\
\hline 750 & $12.67 \pm 2.158$ & $22.833 \pm 1.747$ & $17.5 \pm 0.926$ & $26.667 \pm 2.437$ \\
\hline 1,000 & $14.17 \pm 2.158$ & $24.167 \pm 1.747$ & $23 \pm 0.926$ & $31 \pm 2.437$ \\
\hline 1,500 & $15.83 \pm 2.158$ & $25.667 \pm 1.747$ & $24.167 \pm 0.926$ & $32.333 \pm 2.437$ \\
\hline
\end{tabular}




\begin{tabular}{|c|c|c|c|c|c|c|c|}
\hline \multicolumn{8}{|c|}{ TABLE V } \\
\hline & \multirow[b]{2}{*}{ Shots } & \multicolumn{3}{|c|}{$24 \mathrm{~h}$ ( $p$-values) } & \multicolumn{3}{|c|}{$48 \mathrm{~h}$ (p-values) } \\
\hline & & Mean square & $\mathrm{F}$ & Significance & Mean square & $F$ & Significance \\
\hline \multirow{6}{*}{ 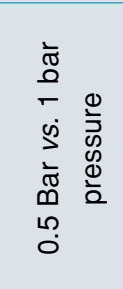 } & 100 & 208.33 & 8.89 & $0.014^{*}$ & 705.33 & 21.07 & $0.001^{*}$ \\
\hline & 250 & 363.00 & 19.14 & $0.001^{*}$ & 408.33 & 126.29 & $0.002^{\star \star}$ \\
\hline & 500 & 243.00 & 16.91 & $0.002^{*}$ & 280.33 & 23.69 & $0.001^{*}$ \\
\hline & 750 & 310.08 & 15.04 & $0.003^{*}$ & 252.08 & 14.42 & $0.004^{*}$ \\
\hline & 1,000 & 300.00 & 7.58 & $0.020^{*}$ & 192.00 & 7.74 & $0.019^{*}$ \\
\hline & 1,500 & 290.08 & 9.54 & $0.011^{*}$ & 200.08 & 6.02 & $0.034^{*}$ \\
\hline
\end{tabular}

\begin{tabular}{|c|c|c|c|c|c|}
\hline \multicolumn{6}{|c|}{$\begin{array}{c}\text { TABLE IV } \\
\text { Time- and dose-dependent comparison of genotoxic damage between control and } \\
\text { experimental groups }\end{array}$} \\
\hline \multirow{2}{*}{\multicolumn{2}{|c|}{ Control vs. }} & \multicolumn{2}{|c|}{$24 \mathrm{~h}$} & \multicolumn{2}{|c|}{$48 \mathrm{~h}$} \\
\hline & & Mean $\pm S E$ & $p$ & Mean $\pm S E$ & $p$ \\
\hline \multirow{6}{*}{ 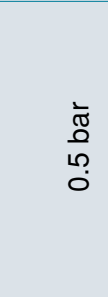 } & 100 & $0.001 \pm 3.051$ & 1.000 & $-6.167 \pm 1.310^{*}$ & 0.001 \\
\hline & 250 & $-1.667 \pm 3.051$ & 0.588 & $-9.667 \pm 1.310^{*}$ & 0.001 \\
\hline & 500 & $-4.667 \pm 3.051$ & 0.135 & $-11.667 \pm 1.310^{*}$ & 0.001 \\
\hline & 750 & $-5.167 \pm 3.051$ & 0.099 & $-13.333 \pm 1.310^{*}$ & 0.001 \\
\hline & 1,000 & $-6.667 \pm 3.051^{*}$ & 0.036 & $-18.833 \pm 1.310^{*}$ & 0.001 \\
\hline & 1,500 & $-8.333 \pm 3.051^{*}$ & 0.001 & $-20.000 \pm 1.310^{*}$ & 0.001 \\
\hline \multirow{6}{*}{ 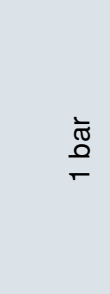 } & 100 & $-8.333^{*} \pm 2.396$ & 0.001 & $-21.500^{*} \pm 3.204$ & 0.001 \\
\hline & 250 & $-12.667^{\star} \pm 2.396$ & 0.001 & $-21.333^{*} \pm 3.204$ & 0.001 \\
\hline & 500 & $-13.667^{\star} \pm 2.396$ & 0.001 & $-21.333^{*} \pm 3.204$ & 0.001 \\
\hline & 750 & $-15.333^{\star} \pm 2.396$ & 0.001 & $-22.500^{\star} \pm 3.204$ & 0.001 \\
\hline & 1,000 & $-16.667^{*} \pm 2.396$ & 0.001 & $-26.833^{*} \pm 3.204$ & 0.001 \\
\hline & 1,500 & $-18.167^{\star} \pm 2.396$ & 0.001 & $-28.167^{\star} \pm 3.204$ & 0.001 \\
\hline
\end{tabular}

\section{DISCUSSION}

The positive effects of ESWT in many areas, particularly in the musculoskeletal system and chronic wounds, led to the investigation of the physical and biological effects of this method at the cellular and tissue level. Several studies in the literature have mainly evaluated the effects of fESW, and there are many questions to be answered about the molecular and cellular effects of rESW. ${ }^{[16,19,25,26,31]}$

In the current in vitro study, we showed rESW application reduced cell viability and delayed wound healing independently of the pressure level. The lowest viability values reached in the highest number of shots at each pressure level and time interval.
In addition, in this study, for the first time in the literature, ${ }^{[32]}$ we demonstrated the genotoxic effect of shock wave application on fibroblasts under in vitro conditions using the comet assay. An increase in comet assay scores was accepted as an increase in genotoxic damage. In cell culture, a gold-standard protocol for rESW application has not been established; therefore, we determined a wide range of shock wave numbers to better demonstrate the rESW effects.

The increasing clinical use of ESWT in recent years has aroused interest in its effects on wound healing and wound care. In their study, Aschermann et al., ${ }^{[16]}$ after applying 0, 375, 750, and 1,500 pulses of rESW, waited 18 to $24 \mathrm{~h}$ for the detachment and 
re-attachment of the cells from the plate and, then, they formed the in vitro wound assay. The authors showed that fibroblast migration increased and, thus, in vitro wound healing increased in all groups after $48 \mathrm{~h}$ of follow-up. Contrary to their results, we showed in vitro wound healing (fibroblast migration) decreased in all groups, regardless of the number of shots. Although in our study, it was confirmed that fibroblasts did not separate from the base after each rESW application, the reason for this difference between the results may be that we first created the scratch assay and then performed rESW application. In addition, we believe that the reason for the decrease in fibroblast migration in our study is the decrease in viability and changes in the cytoskeleton due to the effect of cavitation. On the other hand, only fibroblasts are evaluated in the in vitro scratch assay. However, many cells such as neutrophils and macrophages play an active role in in vivo wound healing. Tepekoylu et al. ${ }^{[33]}$ showed that shock wave therapy increased macrophage recruitment to the wound area by increasing the pivotal macrophage recruitment factors such as macrophage migration inhibitory factor and macrophage inflammatory protein 1 beta. The effect of shock wave therapy on enhancing in vivo wound healing may be due to the contribution of cytokines secreted from increased macrophages to the wound healing process.

In the literature, there are studies examining the effects of rESW application on cell viability. Hochstrasser et al. ${ }^{[25]}$ examined the effect of rESW application in an in vitro study using human fetal foreskin fibroblasts (HFFF2). In their study, fibroblasts stimulated with a frequency of $1 \mathrm{~Hz}$ and $100,200,500$, and 5,000 pulses shock waves were applied at a 2.5-bar pressure level. Cell viability was evaluated with the trypan blue exclusion assay. Viability decreased within the first 1 to $2 \mathrm{~h}$ after the application, regardless of the number of shock waves. In another study in which human dermal fibroblasts were used, 300, 1,000 and 2,000 pulses shock waves were applied and, $1 \mathrm{~h}$ after the application, fibroblast viability was evaluated by using MTT method. ${ }^{[26]}$ It was reported that viability decreased independently of the energy level and the greatest decrease was observed in the highest number of shock waves. Studies in the literature have also emphasized that with the increase in the number of shock waves applied, the viability decreases, and the main determinant of the viability is the shock wave number. ${ }^{[19]}$ In the current study, we showed that rESW application reduced cell viability compared to the control group independently of the pressure level when 250 or more shots were applied, and the lowest viability was achieved at the highest number of shots at both pressure levels. Therefore, it would be appropriate not to exceed 100 shots in rESW studies that are desired to be performed without changing cell viability. Our results seem to be compatible with previous studies. ${ }^{[16,19,25,26]}$ The early cytotoxic effect seen immediately after rESW application suggests that rESW causes cell death by creating mechanical cell damage mediated by cavitation effect. The possible cause of cytotoxicity may be an increase in cell membrane permeability as a result of the direct effect of the shock wave in the first phase of ESW application, as well as acute disorganization of the cytoskeleton that cannot be repaired.

There are many studies in the literature investigating the effects of rESW application on different cell types. These studies usually evaluate cell viability, effects on cell proliferation, chemokine, and cytokine responses to shock wave application, activating and inhibiting cellular pathways, changes in gene expression, while there is no study on the genotoxic effect of shock wave on the cell in the literature. ${ }^{[34-36]}$ In this study, we demonstrated the genotoxic effect of shock wave application on fibroblasts by the comet assay. According to our results, regardless of the number of shock waves applied, genotoxic effects were observed at the end of $48 \mathrm{~h}$ in both pressure groups. In the in vitro study of Ashermann et al., ${ }^{[16]}$ fibroblasts increased gene expression and proteins that regulate the cell cycle in response to the shock wave, thereby attempting to achieve genome stability. These findings are also consistent with our study. Genotoxic damage can be caused by direct physical effects, permeability changes, ionizing molecules and resulting soluble radicals created by ESW application on the cell. In addition, high-energy shock wave application may cause apoptosis or necrosis through genotoxic damage. According to the results obtained from this study, the severity of the genotoxic damage was directly affected by the pressure increase and 1,000 shots at 0.5 bar pressure were considered as the threshold value for genotoxic damage in in vitro conditions. Since the genotoxic effect of the application up to 1,000 shots at 0.5 bar pressure occurred significantly at the $48 \mathrm{~h}$, it was thought that this application might stimulate apoptosis in the cells. On the other hand, genotoxic damage occurring in the first $24 \mathrm{~h}$ in all groups may be associated with necrosis. Therefore, we recommend staying below 1,000 shots for therapeutic effect studies and using shots above 1,000 at 0.5 bar or, regardless of the shot number, 1 bar pressure should 
be used in experimental studies to induce genotoxic damage. Mechanisms of genotoxic damage caused by ESW application should be clarified in future studies.

More intriguingly, in an experimental study of rats with spinal cord damage, low-energy ESW application increased angiogenesis by increasing vascular endothelial growth factor expression in nerve cells, thus improving locomotor and sensory functions. ${ }^{[37]}$ Finally, in an in vivo study, Haberal et al. ${ }^{[38]}$ reported that shock wave therapy applied in rats with lumbar laminectomy reduced epidural fibrosis. The reason for the decrease in epidural fibrosis in this study may be the fibroblast death due to the genotoxic damage observed in the current study, and the possible effect of inflammation triggered by this cytotoxic effect on wound healing.

Nonetheless, this study has some limitations. Our research is based on in vitro experimentation and cannot be linked to in vivo conditions. In vivo wound healing is a complex process and not only through fibroblasts, and it depends on tissue architecture and composition of extracellular matrix. With chemokines and cytokines secreted from endothelial cells, cell-cell interactions and the barrier effect created by living tissues and changes in tissue integrity are both effective on in vivo results. In addition, different experimental setups can be used in in vitro rESW applications. Water bath setup, which is the method frequently used in the literature, was not used in this study, that may have affected the experimental results. Finally, comparing the results obtained from the in vivo study to be performed simultaneously with the in vitro study could provide a better examination of the mechanism of action.

In conclusion, the present study demonstrated the effect of rESW application on fibroblast viability, wound healing and fibroblast genotoxicity using MTT assay, in vitro scratch assay, and comet assay. According to these results, wound healing was delayed and cell viability decreased at all pressure levels, all shot numbers, and all time intervals in fibroblast cultures applied rESW in the in vitro setting. In addition, the severity of genotoxic damage increased proportionally with the increased pressure level. We believe that this study is valuable, as it is the first to reveal the genotoxic effects of rESW application in vitro. By using different energy and impulse regimes and in vivo studies, more useful data can be obtained and the effects of rESW application can be clearly demonstrated.

\section{Declaration of conflicting interests}

The authors declared no conflicts of interest with respect to the authorship and/or publication of this article.

\section{Funding}

This study was approved by Baskent University Institutional Review Board (Project no: DA18/32) and supported by Başkent University Research Fund.

\section{REFERENCES}

1. Auersperg V, Trieb K. Extracorporeal shock wave therapy: An update. EFORT Open Rev 2020;5:584-92.

2. Biedermann R, Martin A, Handle G, Auckenthaler T, Bach C, Krismer M. Extracorporeal shock waves in the treatment of nonunions. J Trauma 2003;54:936-42.

3. Cacchio A, Giordano L, Colafarina O, Rompe JD, Tavernese E, Ioppolo F, et al. Extracorporeal shock-wave therapy compared with surgery for hypertrophic long-bone nonunions. J Bone Joint Surg [Am] 2009;91:2589-97.

4. Furia JP. High-energy extracorporeal shock wave therapy as a treatment for chronic noninsertional Achilles tendinopathy. Am J Sports Med 2008;36:502-8.

5. Valchanou VD, Michailov P. High energy shock waves in the treatment of delayed and nonunion of fractures. Int Orthop 1991;15:181-4.

6. Moretti B, Notarnicola A, Moretti L, Giordano P, Patella V. A volleyball player with bilateral knee osteochondritis dissecans treated with extracorporeal shock wave therapy. Chir Organi Mov 2009;93:37-41.

7. Alves EM, Angrisani AT, Santiago MB. The use of extracorporeal shock waves in the treatment of osteonecrosis of the femoral head: A systematic review. Clin Rheumatol 2009;28:1247-51.

8. D'Agostino C, Romeo P, Amelio E, Sansone V. Effectiveness of ESWT in the treatment of Kienböck's disease. Ultrasound Med Biol 2011;37:1452-6.

9. Kang S, Gao F, Han J, Mao T, Sun W, Wang B, et al. Extracorporeal shock wave treatment can normalize painful bone marrow edema in knee osteoarthritis: A comparative historical cohort study. Medicine (Baltimore) 2018;97:e9796.

10. Gerdesmeyer L, Frey C, Vester J, Maier M, Weil L Jr, Weil $\mathrm{L}$ Sr, et al. Radial extracorporeal shock wave therapy is safe and effective in the treatment of chronic recalcitrant plantar fasciitis: Results of a confirmatory randomized placebo-controlled multicenter study. Am J Sports Med 2008;36:2100-9.

11. Tornese D, Mattei E, Lucchesi G, Bandi M, Ricci G, Melegati G. Comparison of two extracorporeal shock wave therapy techniques for the treatment of painful subcalcaneal spur. A randomized controlled study. Clin Rehabil 2008;22:780-7.

12. Rompe JD, Furia J, Maffulli N. Eccentric loading compared with shock wave treatment for chronic insertional achilles tendinopathy. A randomized, controlled trial. J Bone Joint Surg [Am] 2008;90:52-61.

13. Albert JD, Meadeb J, Guggenbuhl P, Marin F, Benkalfate $\mathrm{T}$, Thomazeau $\mathrm{H}$, et al. High-energy extracorporeal shock-wave therapy for calcifying tendinitis of the rotator cuff: A randomised trial. J Bone Joint Surg [Br] 2007;89:335-41.

14. Vulpiani MC, Nusca SM, Vetrano M, Ovidi S, Baldini R, Piermattei $\mathrm{C}$, et al. Extracorporeal shock wave therapy vs 
cryoultrasound therapy in the treatment of chronic lateral epicondylitis. One year follow up study. Muscles Ligaments Tendons J 2015;5:167-74.

15. Wong CW, Ng EY, Fung PW, Mok KM, Yung PS, Chan KM. Comparison of treatment effects on lateral epicondylitis between acupuncture and extracorporeal shockwave therapy. Asia Pac J Sports Med Arthrosc Rehabil Technol 2016;7:21-6.

16. Aschermann I, Noor S, Venturelli S, Sinnberg T, Mnich CD, Busch C. Extracorporal shock waves activate migration, proliferation and inflammatory pathways in fibroblasts and keratinocytes, and improve wound healing in an open-label, single-arm study in patients with therapy-refractory chronic leg ulcers. Cell Physiol Biochem 2017;41:890-906.

17. Saggini R, Saggini A, Spagnoli AM, Dodaj I, Cigna E, Maruccia $M$, et al. Extracorporeal shock wave therapy: An emerging treatment modality for retracting scars of the hands. Ultrasound Med Biol 2016;42:185-95.

18. Zhao JC, Zhang BR, Hong L, Shi K, Wu WW, Yu JA. Extracorporeal shock wave therapy with low-energy flux density inhibits hypertrophic scar formation in an animal model. Int J Mol Med 2018;41:1931-8.

19. Frairia R, Berta L. Biological effects of extracorporeal shock waves on fibroblasts. A review. Muscles Ligaments Tendons J 2012;1:138-47.

20. Schmitz C, Császár NB, Milz S, Schieker M, Maffulli N, Rompe JD, et al. Efficacy and safety of extracorporeal shock wave therapy for orthopedic conditions: A systematic review on studies listed in the PEDro database. Br Med Bull 2015;116:115-38.

21. Simplicio CL, Purita J, Murrell W, Santos GS, Dos Santos RG, Lana JFSD. Extracorporeal shock wave therapy mechanisms in musculoskeletal regenerative medicine. J Clin Orthop Trauma 2020;11(Suppl 3):S309-S318.

22. Fischer S, Mueller W, Schulte M, Kiefer J, Hirche C, Heimer S, et al. Multiple extracorporeal shock wave therapy degrades capsular fibrosis after insertion of silicone implants. Ultrasound Med Biol 2015;41:781-9.

23. Mittermayr R, Hartinger J, Antonic V, Meinl A, Pfeifer S, Stojadinovic A, et al. Extracorporeal shock wave therapy (ESWT) minimizes ischemic tissue necrosis irrespective of application time and promotes tissue revascularization by stimulating angiogenesis. Ann Surg 2011;253:1024-32.

24. Yang G, Luo C, Yan X, Cheng L, Chai Y. Extracorporeal shock wave treatment improves incisional wound healing in diabetic rats. Tohoku J Exp Med 2011;225:285-92.

25. Hochstrasser T, Frank HG, Schmitz C. Dose-dependent and cell type-specific cell death and proliferation following in vitro exposure to radial extracorporeal shock waves. Sci Rep 2016;6:30637.

26. Berta L, Fazzari A, Ficco AM, Enrica PM, Catalano MG, Frairia R. Extracorporeal shock waves enhance normal fibroblast proliferation in vitro and activate mRNA expression for TGF-beta1 and for collagen types I and III. Acta Orthop 2009;80:612-7.

27. Nwokeoha S, Carlisle R, Cleveland RO. The application of clinical lithotripter shock waves to RNA nucleotide delivery to cells. Ultrasound Med Biol 2016;42:2478-92.

28. Vetrano M, d'Alessandro F, Torrisi MR, Ferretti A, Vulpiani MC, Visco V. Extracorporeal shock wave therapy promotes cell proliferation and collagen synthesis of primary cultured human tenocytes. Knee Surg Sports Traumatol Arthrosc 2011;19:2159-68.

29. Akdeniz SS, Beyler E, Korkmaz Y, Yurtcu E, Ates U, Araz K, et al. The effects of ozone application on genotoxic damage and wound healing in bisphosphonate-applied human gingival fibroblast cells. Clin Oral Investig 2018;22:867-73.

30. Kiziltan E, Yurtcu E. Semi-automatic scoring tool for comet assay. Journal of Serbian Society for Computational Mechanics 2015;9:27-33.

31. Zhang L, Fu XB, Chen S, Zhao ZB, Schmitz C, Weng CS. Efficacy and safety of extracorporeal shock wave therapy for acute and chronic soft tissue wounds: A systematic review and meta-analysis. Int Wound J 2018;15:590-9.

32. Atik OŞ. Is there something new and interesting in my article? Eklem Hastalik Cerrahisi 2019;30:69.

33. Tepeköylü C, Lobenwein D, Blunder S, Kozaryn R, Dietl $\mathrm{M}$, Ritschl $\mathrm{P}$, et al. Alteration of inflammatory response by shock wave therapy leads to reduced calcification of decellularized aortic xenografts in micet. Eur J Cardiothorac Surg 2015;47:e80-90.

34. Leone L, Vetrano M, Ranieri D, Raffa S, Vulpiani MC, Ferretti A, et al. Extracorporeal Shock Wave Treatment (ESWT) improves in vitro functional activities of ruptured human tendon-derived tenocytes. PLoS One 2012;7:e49759.

35. Rohringer S, Holnthoner W, Hackl M, Weihs AM, Rünzler D, Skalicky S, et al. Molecular and cellular effects of in vitro shockwave treatment on lymphatic endothelial cells. PLoS One 2014;9:e114806.

36. Weihs AM, Fuchs C, Teuschl AH, Hartinger J, Slezak $\mathrm{P}$, Mittermayr R, et al. Shock wave treatment enhances cell proliferation and improves wound healing by ATP release-coupled extracellular signal-regulated kinase (ERK) activation. J Biol Chem 2014;289:27090-104.

37. Yahata K, Kanno H, Ozawa H, Yamaya S, Tateda S, Ito K, et al. Low-energy extracorporeal shock wave therapy for promotion of vascular endothelial growth factor expression and angiogenesis and improvement of locomotor and sensory functions after spinal cord injury. J Neurosurg Spine 2016;25:745-55.

38. Haberal B, Şimşek EK, Akpınar K, Türkbey Şimşek D, Şahintürk F. Impact of radial extracorporeal shock wave therapy in post-laminectomy epidural fibrosis in a rat model. Jt Dis Relat Surg 2021;32:162-9. 